these were reviewed by the authors $98 \%$ were detected. These results led the authors to question the policy of applying plaster-of-Paris to the wrists of patients with pain after injury when the radiographs show no fracture. They suggest that the fractures that are missed are incomplete fractures and that these heal well anyway. They had a 5\% incidence of nonunion; all such cases were in men, with a mean age of 22 .

Leslie and Dickson's paper confirms the findings of others in showing that the outlook for this fracture is not as bad as was thought at one time. They also reaffirm that surgery is rarely necessary provided that the fracture is immobilised for the appropriate length of time and that displacement does not occur. Immobilisation for a maximum of 12 weeks is now regarded as adequate. If union has not been achieved by that time the patient's wrist should be mobilised. If it is pain free no further action is required, surgery being required only for pain. Union may eventually occur in about a year in the painfree wrist which is mobilised.

Teaching dogma about immobilisation of injured wrists need not, however, be revised. Doctors in accident departments need firm guidelines. All patients who have injured their wrists and are tender in the anatomical snuff box should be regarded as having fractured their scaphoid until proved otherwise. This may require the wrist to be plastered for two weeks, the plaster being removed then and radiography repeated. Quite reasonably, patients do not like being told that a fracture has been "missed," especially if there are late complications. Patients do understand and appreciate caution-even if it requires the inconvenience of plaster-of-Paris for two weeks.

${ }^{1}$ Leslie IJ, Dickson RA. The fractured carpal scaphoid. Natural history and factors influencing outcome. F Bone foint Surg (Br) 1981 ;63B:225-30.

\section{Undergraduate medical education in genitourinary medicine}

Since the early 1950s the number of new cases registered at clinics for genitourinary medicine or sexually transmitted disease in Britain has increased fourfold. While syphilis has remained uncommon the frequency of gonorrhoea increased dramatically during the 1960 s and early 1970s but then levelled off with a peak of almost 66000 new cases in 1971. ${ }^{1}$ Substantial rises have also occurred in the numbers of cases of non-specific urethritis in men and so-called non-specific genital infection in women. High though the prevalence rates may appear they are lower than in many other countries. Another problem has been the development of antimicrobial resistance in gonococci and the appearance of totally penicillin-resistant $\beta$-lactamaseproducing gonococci. These were first reported in 1976. Only 31 isolates were reported in 1978, but 104 were recorded in 1979 and 210 in 1980 - a remarkable increase. ${ }^{2}$

These figures form a sombre background to a recent survey of the teaching of genitourinary medicine to undergraduate medical students in Britain. ${ }^{3}$ Teachers in 26 of the 30 medical schools completed a self-administered questionnaire. All schools provided lectures, the number varying from one to 16 , nine having four or fewer lectures and 12 having five or fewer lectures with attendance varying from fewer than 20 up to 260 students. In four schools the teachers of genitourinary medicine had no courses of their own, merely contributing lectures to other courses. This restriction, which none of them wanted, greatly limited the scope of their teaching and was apparently due to lack of time. Attendance at an outpatient clinic is a vital part of training, reinforcing the theoretical knowledge, showing the student how to take a sexual history, to manage patients, and especially providing an understanding of sexual behaviour. Attendance varied from one or two hours to a maximum of 40 hours with a mean of 10 . In $70 \%$ of the schools only one student was allocated to each doctor. Three schools provided audiovisual teaching material, and most offered electives. The mean total teaching time (lectures plus clinical attachment) was 15 hours; despite the increasing clinical case load, this shows little change from the mean total teaching time of 19 hours in $1966 .{ }^{4}$ In half the schools there was some form of assessment at the end of the course and questions were included in the final MB examination paper at some time; only two schools had examiners on genitourinary medicine in the clinical or oral final examination.

These findings should prompt deans of all medical schools to review the time and facilities for teaching undergraduate medical students, especially in those schools without courses in genitourinary medicine. Greater emphasis on the sexually transmitted diseases in final examinations would provide greater stimulus to learning. The crucial question, however, is how well undergraduate training equips young doctors to manage patients with suspected sexually transmitted or allied diseases. Undergraduate instruction must state the principles, which include accurate diagnosis using clinical examination and laboratory investigation, effective treatment, careful follow-up to ensure cure, and rapid, accurate contact tracing. It is the application of these principles that has kept prevalence rates relatively low in Britain. Doctors must also be prepared to counsel their patients on sexual and social problems.

Fortunately Britain still has the best open-access nationwide free clinic service in the world. Patients present themselves, are referred, or attend after contact training. Clinics are supervised by consultants who work whole time in the specialty. There will always be a few patients who wish to be treated by their NHS general practitioner or privately, and a few nonspecialists who wish to treat patients for sexually transmitted diseases. At present in Britain the demand for these services is small-and most non-specialist doctors realise the difficulties of practising to the high standards of the clinics. Nevertheless, undergraduate training must provide a sound foundation for all doctors to know when to suspect sexually transmitted diseases, which may impinge on so many general and specialist medical disciplines. Older doctors, as well as the new generation, need to realise that the old stigma-ridden VD clinic has been replaced by a modern department, often called a department of genitourinary medicine to help to remove past prejudices.

1 Anonymous. Sexually transmitted disease surveillance 1979. $\mathrm{Br} \mathrm{Med} f$ $1981 ; 282: 155-6$.

2 Communicable Disease Surveillance Centre. B-Lactamase producing gonococci-July-December 1980. Communicable Disease Report 1981; No 5 .

3 Adler MW, Willcox RR. Teaching of genitourinary medicine (venereology), to undergraduate medical students in the United Kingdom. $\mathrm{Br} \mathcal{F}$ Vener Dis (in press).

4 Webster B. Teaching of venereal diseases in medical schools throughout the world. Preliminary report. A study done under the auspices of the International Union against the Venereal Diseases and the Treponematoses, with the co-operation of the World Health Organisation. $\mathrm{Br} \mathcal{F}$ Vener Dis $1966 ; 42: 132-3$. 